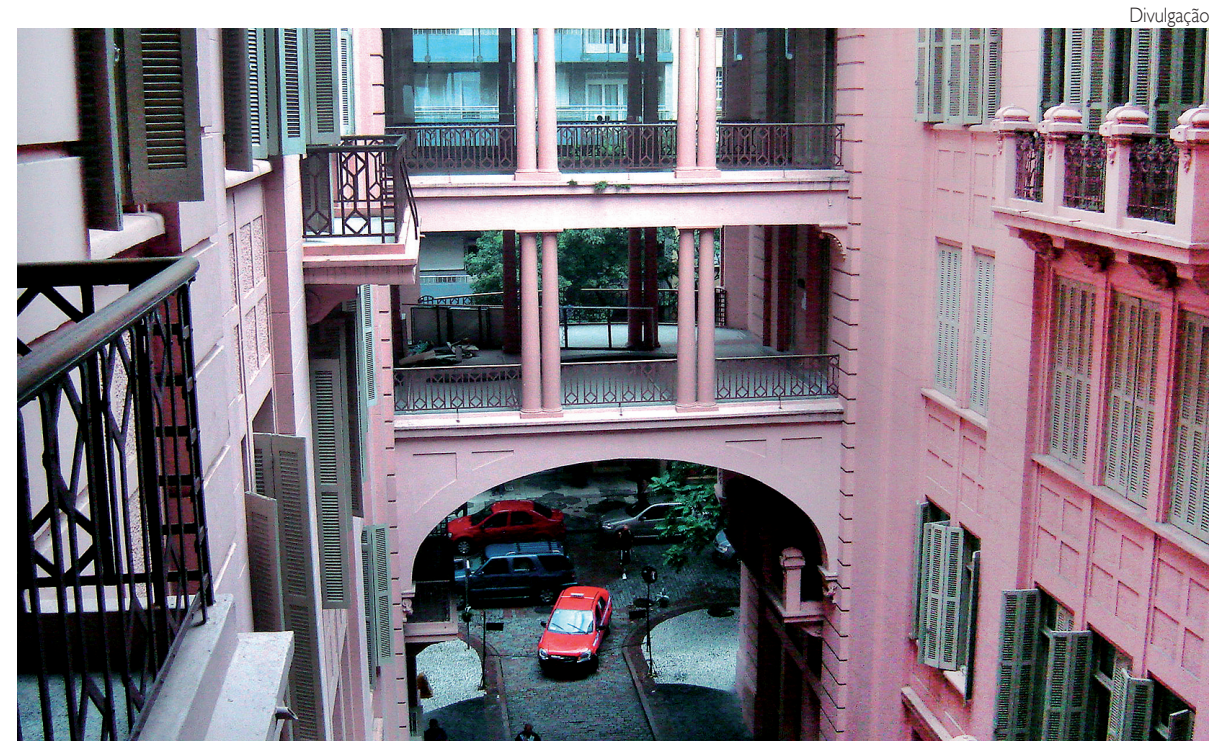

Hotel Majestic, em Porto Alegre, onde está a Casa de Cultura Mário Quintana

\title{
CASA-MUSEU
}

\section{JANELA QUASE INDISCRETA PARA VIDA DE QUEM FICOU PARA A HISTÓRIA}

$\mathrm{O}$ xale pendurado na cadeira do quarto de Renoir, o livro aberto na escrivaninha de Pablo Neruda, rosas frescas colhidas no jardim da Casa de Rui Barbosa sugerem uma presença, como se o proprietário tivesse dado só uma saidinha, para voltar logo mais. Este é o espírito que norteia a criação de uma casa-museu: manter viva a lembrança de um personagem - seja ele um artista, um homem público ou até mesmo um homem comum - transformando sua moradia num museu. "As casas e todos os elementos que as compõem têm uma força extraordinária, sobrevivem aos moradores e passam a dar sobre eles o seu testemunho", conta Mário Chagas, diretor de processos museais do Instituto Brasileiro de Museus
(Ibram). "As casas-museus e os seus objetos servem para evocar nos visitantes lembranças de seus antigos habitantes, de seus hábitos, sonhos, alegrias e tristezas, lutas, derrotas e vitórias; mas servem também para evocar lembranças das casas que o visitante habitou e que hoje o habitam”, afirma o pesquisador.

$\mathrm{O}$ processo que transforma uma moradia em um museu é dado pela potência política e poética que um personagem é capaz de produzir na memória local, regional ou nacional. Segundo Rosaelena Scarpeline, pesquisadora do Centro de Memória da Universidade Estadual de Campinas (Unicamp), casas-museus são iniciativas para a preservação da memória individual, acervos particulares de personalidades, artistas, políticos, enfim, personagens que se destacam e que tenham papel relevante para a comunidade. A casa revela. Recupera o espírito do morador e o momento histórico no qual ele está inserido ao reproduzir seu cotidiano, suas práticas culturais e sociais.

INSPIRAÇÃo Foi por conta dessa potência que a pequena casa de madeira, perdida no meio de um seringal, em Xapuri (AC), onde viveu e também foi assassinado o seringueiro Chico Mendes, foi transformada em um lugar de memória, a CasaMuseu Chico Mendes. Na proposta museológica optou-se por manter a casa tal qual ela estava no dia da morte de Chico Mendes, como uma espécie de encenação de uma tragédia. Para Mário Chagas, por meio da casa, Chico Mendes pode ter novo corpo, capaz de denunciar os desmatamentos e organizar ações de defesa da posse da terra. "O lugar transformou-se em local de peregrinação e uma fonte de inspiração, capaz de propiciar novas experiências, de motivar novas atitudes", conta. Em texto escrito para a revista $I_{s t o E}$, em 1984, Mário Quintana dizia que todo conhecimento sobre ele estava em seus livros. "Minha vida está nos meus poemas, meus poemas são eu mesmo, nunca escrevi uma vírgula que não fosse uma confissão", declarou.

A Casa de Cultura Mário Quintana abriga um amplo acervo da obra do poeta, com fotografias, ilustrações, pinturas, caricaturas e poemas gravados em fita K7, LP e CD, além de fitas VHS com depoimentos e entrevistas. Entretanto, na tentativa de criar mais 
um caminho para conhecer o autor, a Casa de Cultura reconstituiu e abriu à visitação o último quarto onde o poeta morou (de 1968 a 1980) no Hotel Majestic, em Porto Alegre. Ali está o papel amassado na lixeira, a desordem na cama, o cinzeiro ainda sujo. Entrar num espaço assim pode até evocar um sentimento de invasão de privacidade. "A casa, como lugar de memória, será capaz de revelar os mistérios de seu proprietário, tão cuidadosamente arrumados e conservados em seu interior. Visitá-la é penetrar nesse mundo particular, como um intruso pairando sob seu cotidiano íntimo", afirma Rosaelena Scarpeline. Esta sensação também pode ser vivenciada na Casa Guilherme de Almeida, museu na cidade de São Paulo que preserva intacta a casa onde viveu o poeta até 1969, ano de sua morte. Além de promover a obra desse que é um dos mentores do movimento modernista brasileiro, a Casa oferece cursos, oficinas e palestras relacionadas ao seu campo de atuação: a poesia e a tradução.

INVASÃO DA PRIVACIDADE Amigos mais íntimos de Pablo Neruda dizem que ele não gostava que entrassem na cozinha de nenhuma de suas casas em Valparaíso, Isla Negra e em Santiago, no Chile. Para o poeta, a cozinha era um espaço íntimo e privado. Transformadas em casas museus e mantidas pela Fundação Pablo Neruda, esse desejo do poeta é mantido. Assim as centenas de turistas que visitam as casas todos os anos não podem visitar a cozinha. Como se fora um amigo do escritor, o visitante vivencia o cotidiano da casa, a atmosfera criada pelos hábitos impressos, pelos móveis, livros e pela imensa coleção de objetos que Neruda coletava em suas viagens pelo mundo. "Quando entramos em uma casa-museu também acessamos uma dimensão onírica, poética, levamos junto as casas que estão dentro de nós, tal qual caramujos. Isso nos permite comparar o local visitado e nos reconhecer", acredita Mário Chagas.

PIONEIRISMO Esse efeito é dado por uma narrativa histórica que busca o reconhecimento por parte da comunidade na qual a casa-museu está inserida. "Dessa forma espera-se que o personagem não caia no esquecimento e faça parte da memória coletiva local, tornando-se digna de reconhecimento e preservação", explica Rosaelena, que estudou o processo de transformação do lugar onde morava Rui Barbosa, em Botafogo, Rio de Janeiro, na primeira casa-museu institucionalizada no país, em 1929. Mas a primeira iniciativa de preservar um espaço de moradia para transformá-lo em espaço de memória ocorreu com a casa de Benjamin Constant (18361891), estadista brasileiro, localiza-
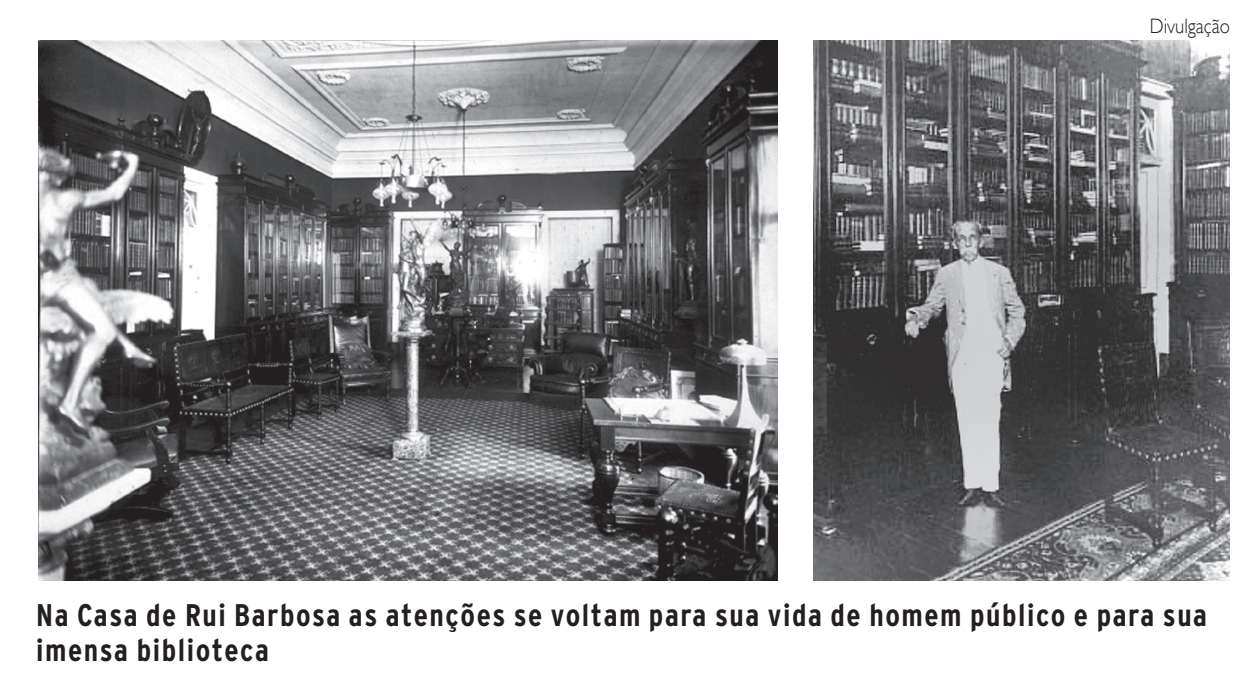

Na Casa de Rui Barbosa as atenções se voltam para sua vida de homem público e para sua imensa biblioteca

da no bairro de Santa Tereza, Rio de Janeiro, e que foi protegida no texto da Constituição de 1891. A criação da Casa-Museu Benjamin Constant, porém, só aconteceu em 1972.

"À medida que se seleciona o conjunto de objetos a serem mostrados, os aspectos da personalidade a serem evidenciados e os espaços a serem visitados, é criado um 'mundo presumido' que serve para dar destaque ao personagem, ao mito e/ou homem público, e que pode ou não apresentar aspectos de seu mundo privado e familiar", aponta Rosaelena.

Independente da proposta escolhida, o importante é evitar a cristalização. Isso, sim, pode significar a morte do homenageado. Segundo o diretor do Ibram, Mário Chagas, a casa tem que manter vivo o espírito do personagem por meio de um diálogo com o presente. "Isso é mais importante do que preservar os aspectos materiais", enfatiza. "Para manter uma casa-museu viva é preciso olhar não só para o seu interior, mas, por meio de suas janelas, enxergar o mundo".

\section{Patrícia Mariuzzo}

